\title{
Influence of Workers' Attitude towards Time and Work on Perceived Job Performance in Private and Public Sectors
}

\author{
Benjamin O. Omolayo (Corresponding author) \\ Department of Psychology \\ Faculty of the Social Sciences \\ Ekiti State University \\ Ado-Ekiti, Nigeria \\ Tel: +234-803-389-8781Ｅ-mail: droluomolayo@yahoo.com
}

Adedayo A. Oluwafemi

Department of Psychology

Faculty of the Social Sciences

University of Ibadan

Ibadan, Nigeria

Tel: +234-803-463-2566_E-mail: oluwafemiadedayo@yahoo.co.uk

Received: June 3, $2012 \quad$ Accepted: June 25, $2012 \quad$ Published: June 30, 2012

doi: $10.5430 / j m s . v 3 n 3 p 2$

URL: http://dx.doi.org/10.5430/jms.v3n3p2

\begin{abstract}
This study was designed to find out the influence of workers' attitude towards time and work on perceived job performance in private and public sectors. One hundred and eighty (180) workers drawn from five (5) different organizations, three (3) from private sector and two (2) from public sector in Ado-Ekiti and Ibadan metropolis were used as samples. Three instruments were used namely Time Attitude Scale (TAS) to measure the attitude of workers toward time; Minnesota Satisfaction Questionnaire (MSQ) to measure job satisfaction which represents workers attitude towards work; and the perceived Job Performance Scale (JPS) to measure workers characteristic, tendencies to work long and hard as means of achieving success rather than their activity during a specific period. T-test for independent groups and regression analysis were employed in analyzing the data collected. Five hypotheses were tested and results shows that there is no significant difference in the attitude of workers towards time in private and public sectors; that there is a significant difference in the attitude of workers towards work in private and public sectors; that there is no significant difference in workers perceived job performance in both private and public sectors; that there is a significant joint influence of workers' attitude towards time and work on perceived job performance in the private sector, there is also a significant independent influence of workers attitude towards time on perceived job performance in the private sector but there is no significant independent influence of workers attitude towards work on perceived job performance in the private sector. It was also found that there is no significant joint and independent influence of workers' attitude towards time and work on perceived job performance in the public sector.
\end{abstract}

Keywords: Attitude, Job Satisfaction, Perceived Job Performance, Private Sector, Public Sector, Time Management, Workers

\section{Introduction}

It is highly prominent in work organizations that time be consciously used because the effective use of time is an important issue in organizational efficiency, organizational effectiveness, understanding human behaviour, education and travel behaviour. Although time use research is a developing field of study but its relevance to work organization shouldn't be ignored, because it's a delicate aspect of life that runs so fast and doesn't come back to replace itself. The question concerns how time is allocated across a number of activities (such as time spent at home, at work, shopping et.c). 
Different people may judge identical length of time quite differently. Time can "fly", that is, a long period of time can seem to go by very quickly. Likewise, time can seems to "drag", especially when one performs a boring task. Therefore, people develop different kinds of attitude towards time and work one way or the other, but the problem lies where a greater number of people develop an unfavourable attitude towards time and work in work organization.

Workers' perception towards time determines whether they will develop favourable or unfavourable attitude towards it, and if in any case one of the kinds of attitude are developed, then it will tell on how productive workers would be in an organization. As workers, groups and departments have different attitude towards time, so also countries have differing attitude towards time. The orientation each workers, groups, departments, and countries have toward time differs relatively with respect to different cultures or norms of each workers, groups, departments and countries.

The effectiveness and efficiency of an organization comes down to the effectiveness and efficiency of individual workers in the organization. The management of time is an issue which is fundamental to job performance, and how a worker manages his/her time will depend literarily on his/her favourable or unfavourable attitude towards time which will invariably influence his/her perceived job performance in an organization.

Taylor promoted the use of time studies when he published his work, the Principles of Scientific Management (1911), in which he described how the application of the scientific method to the management of workers could greatly improve productivity. He argued that the effective use of time studies measure all task movements made by workers and try to eliminate those that do not lead to increased productivity (Taylor, 1911). In other words, the effective use of time by workers leads to increase in productivity while the ineffective use of time can cause decrease in productivity.

County Extension Director's (CEDs) time management practices

$<$ Table 1 about here $>$

A study conducted to examine the time management practices of Pennsylvania County Extension Directors (CEDs) and analyze the relationship between CED time management practices and job performance suggest that the skill of time management is being practiced by Pennsylvania CEDs "sometimes" to "very often". A mean score of 3.81 for the communications dimensions indicates frequent and competent use of time saving communication practices and skills. The measure of 3.23 for all time management practice statements indicates that Pennsylvania CEDs recognize the important practices. Similar findings were reported by Distasio for School Superintendents in Connecticut and Radhakrishna for Maryland CEDs, that CEDs perceived themselves as good performers in their jobs. It is possible to conclude based on the above findings that CEDs perceived themselves to perform their CED responsibilities at a high level and generally their superiors agreed (Distasio, 1985; Radhakrishna, Bagget \& Toder, 1989).

Self (County Extension Directors-CED) and Superior (Assistant Regional Directors-ARD) perception scores

$<$ Table 2 about here $>$

Furthermore, it seems logical to expect similar relationships between time management scores and superiors' ratings of CED job performance. Literature also supports the relationship between time management scores and job performance as evidence by the earlier studies of Islam, Depositario \& Valera (1987) for rural development officers, Noon (1985), Schriber \& Gutek (1987) for business executives, and Radhakrishna, Bagget \& Toder (1989) for Maryland CEDs.

These researchers found significant relationship between management of time or allocation of time to managed tasks and job performance with the conclusion that management of time is a key to managerial performance (Islam et al, 1987; Noon, 1985; Schriber \& Gutek 1987). It can therefore be deduced from the above research that there could be a relationship between workers' attitude towards time and their perceived job performance.

However, the review of time management studies has shown that time management is not a well-defined construct. Also, the quality of measurement instruments was shown to be questionable. Therefore, research has found positive effects of time management behaviour on proximal outcomes, performance, and stress-related outcomes but the results obtained for performance appear to be the weakest within these three categories even though the effect of time management on outcomes such as job performance was not clearly established (Claessens, Eerde, Rutte \& Roe, 2007).

It can therefore be deduced from the above research that there could be a relationship between workers' attitude towards time and their perceived job performance.

One common research finding is that job satisfaction correlates with life satisfaction (Rain, Lane \& Steiner, 1991). This correlation is reciprocal, meaning people who are satisfied with life tend to be satisfied with their job and people who are satisfied with their job tend to be satisfied with life. However, some research has found that job satisfaction is not significantly related to life satisfaction when other variables such as non-work satisfaction and core self-evaluations are taken into account (Rode, 2004). 
Research evidence on job satisfaction and job performance discussed the correlational analysis of the research as incontrovertible evidence that satisfaction and performance are weakly related. Recent meta-analysis by Muchinsky \& Laffaldano(1985) found correlation $r=.17$. Causal analysis suggests that performance is more likely to cause satisfaction than vice-versa (a productive worker is a happy worker) but Christen, Iyer, \& Soberman (2006) found a significant positive effect of job performance on job satisfaction in contrast to how decades of research have failed to find a significant or consistent link between job performance and job satisfaction (Brown \& Peterson 1993; Laffaldano \& Muchinsky 1985).

However, as other literature on the study of job satisfaction and job performance reveals that the relationship between satisfaction and performance are weakly related, so also this study will be looking at the relationship between job satisfaction in respect to workers' attitude towards work, and job performance in respect to the perceived job performance of workers. Job satisfaction is one out of the categories of work attitude and for the purpose of this study it will be used to describe and measure the variable of workers' attitude towards work.

\section{Hypotheses}

1. There will be a significant difference in the attitude of workers' towards time in private and public sectors.

2. There will be a significant difference in the attitude of workers towards work in private and public sectors.

3. There will be a significant difference in workers' perceived job performance in both private and public sectors.

4. Workers' attitude towards time and work will jointly and independently have significant influence on perceived job performance in the private sector

5. Workers' attitude towards time and work will jointly and independently have significant influence on perceived job performance in the public sector.

\section{Research Methods}

\subsection{Design}

This research is an exploratory study which tries to find out the influence of workers' attitude toward time and work on the perceived job performance of workers in private and public sectors. It is a survey design because it makes use of questionnaires to collect the needed data. The dependent variable is perceived job performance while the two independent variables are workers' attitude towards time and work respectively.

\subsection{Participants}

A total of 180 workers of both male and female participants were randomly drawn from Ado-Ekiti (Ekiti State) and Ibadan (Oyo State) metropolis. They were made up of 90 private sector workers and 90 public sector workers respectively with 96 males and 84 females ranging from 18-60 years of age.

\subsection{Instruments}

The instruments used for this study are Time Attitude Scale (TAS), Minnesota Satisfaction Questionnaire (MSQ), and perceived Job Performance Scale (JPS).

The Time Attitude Scale (TAS) is a 13-item questionnaire developed by Oluwafemi (2008). It was designed on a Likert-type rating scale of 5 points rating ranging from "strongly disagree" to "strongly agree". The content validity index of the instrument is .85 while the split-half reliability coefficient alpha is .62 (Oluwafemi, 2008).

The Minnesota satisfaction questionnaire (MSQ) is a 20 -item inventory developed by Weiss, Dawis, England \& Lofquist (1967). The MSQ was adapted for the use of professionals in Nigeria after several years of research at re-standardizing it in order to enhance its suitability and relevance for Nigerians. Weiss et al (1967) provided the psychometric properties for American samples while Mogaji (1997) provided the properties for Nigerian samples. Weiss et al (1967) reported a one week interval test-retest reliability coefficient of 0.89 and one-year interval coefficient of 0.70 . The mean of the Hoyt internal reliability coefficient presented below for the American samples and the 72-day interval for Nigeria samples are also presented in Table 3 below. The scale is subdivided into 3 namely intrinsic satisfaction (I) extrinsic satisfaction (E), and general satisfaction $(\mathrm{G})$

\section{$<$ Table 3 about here $>$}

By correlating the general satisfaction scale of MSQ with the overall score on Job Description Index (JDI) by Smith, Kendall \& Hulin (1969), the concurrent validity coefficients obtained by Wanous (1974) for American samples is 0.71 and by Mogaji (1997) for Nigerian samples is 0.51

The perceived Job Performance Scale (JPS) was developed by Brown \& Leigh (1996). It consists of 10 items and has a Likert-type rating scale of 5 points rating ranging from 'strongly disagree' to 'strongly agree'. The scale is divided into two 
dimensions namely; time commitment and work intensity each consist of five items. The scale has co-efficient alpha of 0.82 , time commitment $(0.86$ and 0.82$) \&$ work intensity $(0.82$ and 0.83$)$. The Cronbach co-efficient alpha yielded a value of 0.60 and the reliability coefficient is 0.66 (Brown \& Leigh, 1996).

\subsection{Procedure}

A total of 200 copies of the questionnaires were administered to private and public sector workers in Ado-Ekiti (Ekiti State) and Ibadan (Oyo State) respectively, but only 180 were valued enough to be used. The participants were asked to tick the column that best express their feelings about each statement and were urged to respond as honestly as possible. They were assured of the confidentiality of their responses.

\subsection{Data analysis}

The t-test for independent groups was used to test hypotheses 1,2, and 3 respectively while regression analysis was used to test hypotheses 4 , and 5 respectively.

\section{Results}

The results of the analyses are presented in Tables 1,2,3,4 and 5 .

Table 4: Summary table of independent t-test analysis showing the difference in the attitude of workers towards time in private and public sectors

$<$ Table 4 about here $>$

Results from Table 4 shows that there is no significant difference in the attitude of workers towards time in private and public sectors.

Table 5: Summary table of independent t-test analysis showing the significant difference in the attitude of workers towards work in private and public sectors

$<$ Table 5 about here $>$

Findings as shown in Table 5 show that there is a significant difference in the attitude of workers towards work in private and public sectors.

Table 6: Summary table of independent t-test analysis showing the significant difference in workers perceived job performance in private and public sectors

$<$ Table 6 about here $>$

In Table 6, results indicated that there is no significant difference in workers perceived job performance in both private and public sectors.

Table 7: Summary table of regression analysis showing the significant influence workers' attitude towards time and work will jointly and independently have on perceived job performance in the private sector

$<$ Table 7 about here $>$

Results from Table 7 shows that there is a significant joint influence of workers' attitude towards time and work on perceived job performance in the private sector. Also, results revealed that there is a significant independent influence of workers attitude towards time on perceived job performance in the private sector but there is no significant independent influence of workers attitude towards work on perceived job performance in the private sector.

Table 8: Summary table of regression analysis showing the significant influence workers' attitude towards time and work will jointly and independently have on perceived job performance in the public sector

$<$ Table 8 about here $>$

Results as indicated in Table 8 shows that there is no significant joint and independent influence of workers' attitude towards time and work on perceived job performance in the public sector.

\section{Discussion}

Although the first hypothesis predicted that there will be a significant difference in the attitude of workers towards time in private and public sectors, this was however not supported by the result obtained from the study carried out. This shows that private and public sector workers elicit similar attitude towards time. This implies that both private and public sector workers know the importance of time and there is no difference in their way of thinking, feeling and acting in respect to the use of time. This finding supports the research findings of Distasio (1985), Islam, Depositario \& Valera (1987), Noon (1985) and Schriber \& Gutek (1987). It also supports the research findings of Radhakrishna, Bagget \& Toder (1989) on 
County Extension Directors (CEDs) of Pennsylvania which suggest that Pennsylvania CEDs "sometimes" to "very often" practice the skill of time management, thereafter a mean score of 3.18 for the communications dimensions indicates frequent and competent use of time saving communication practices and skills, and also that the mean score of 3.23 for all time management practice statements indicates that Pennsylvania CEDs recognize the importance of time through the effective use of time management practices. It all suggests that from the on-going, workers in both private and public sectors understand the importance of time and would have been involved in time management practices for them to have been able to know how to use time effectively.

The second hypothesis tested predicted that there will be a significant difference in the attitude of workers towards work in private and public sectors which the difference was found to be significant. This shows that private and public sector workers elicit different kinds of attitude towards work which might be rather favourable or unfavourable in respect to their extent of job satisfaction. This implies that there are differences in the extent at which private sector workers can be satisfy with their job compare to the public sector workers or vice-versa. From the findings, it can be deduced that private sector workers are more satisfied with their job than public sector workers because private sector workers show a mean of 70.20 which is higher than public sector workers mean that show 64.23. in relation to this considering the standard deviation and the standard error which results in private sector workers having 12.79 for its standard deviation and 1.35 for its standard mean error while the public sector workers shows a higher standard deviation of 15.17 and a higher standard mean error of 1.60 .

Therefore, people (i.e. private sector workers) who are satisfied with life tend to be satisfied with their job and people who are satisfied with their job tend to be satisfied with life. However, some research has found that job satisfaction is not significantly related to life satisfaction when other variables such as non-work satisfaction and core self-evaluations are taken into account (Rode, 2004).

Although, research evidence on job satisfaction and job performance discussed the correlational analysis of the research as incontrovertible evidence that satisfaction and performance are weakly related. Recent meta-analysis by Muchinsky \& Laffaldano(1985) found correlation $r=.17$. Causal analysis suggests that performance is more likely to cause satisfaction than vice-versa (a productive worker is a happy worker) but other factors which include the level of pay and benefits, the perceived fairness of the promotion system, the quality of the working conditions, leadership and social relationships, and the job itself (the variety of tasks involved, the interest and challenge the job generates and the clarity of the job description/requirements) can also contribute to the reason why private sector workers showed favourable attitude towards work than public sector workers.

The third hypothesis which predicted that there will be a significant difference in worker's perceived job performance in both private and public sector workers was rejected because the findings showed no significant difference in worker's perceived job performance in private and public sectors. This implies that there is a similarity in workers perceived job performance of private and public sector workers. From the findings, it relatively means that, the interpretation of the output and quality of job or the way of understanding the output and input provided to create the output by workers in private and public sectors are the same. It means that both private and public sector workers have an understanding of their perceived job performance in their respective organizations.

The fourth hypothesis predicted that workers' attitude towards time and work will jointly and independently have significant influence on perceived job performance in the private sector. This was tested jointly and supported by the result obtained from the study carried out which revealed that there is a joint significant influence of workers' attitude towards time and work on perceived job performance in the private sector, which means that private sector workers attitude towards time and work influence perceived job performance. The result above can be related to Taylor's (1911) scientific management time study which is a means to scientifically determine the optimal way to perform a job by performing experiments that he called time studies. These studies were characterized by the use of a stop watch to time a worker's sequence of motions, with the goal of determining the one best way to perform a job taking "the science of shoveling" experiment as an example of which the result was a three to four fold increase in productivity and workers were rewarded with pay increase. Prior to scientific management theory, workers used their own shovels and rarely had the optimal one for the job. However, there is no significant independent influence of workers attitude towards work on perceived job performance in the private sector but significant independent influence of workers attitude exist towards time on perceived job performance in the private sector. This supports the findings reported by Distasio (1985) for school supervisors and superintendents in Connecticut, and Radhakrishna, Bagget \& Toder (1989) for Maryland which shows a significant relationship between the overall job performance score and time management score. It can be deduced from this finding that a worker in the private sector that is said to be content with his/her job does not know the interpretation of the output and quality of job or the way of understanding the output and input provided to create the output. This is in contrast with 
the findings of Christen, Iyer, \& Soberman (2006) that found a significant positive effect of job performance on job satisfaction but agrees with the decades of research who have failed to find a significant or consistent link between job performance and job satisfaction (Brown \& Peterson 1993; Laffaldano \& Muchinsky 1985).

The significant independent influence of workers attitude towards time on perceived job performance slightly agrees with the review of research that found positive effects of time management behaviour on proximal outcomes, performance, and stress-related outcomes but the results obtained for performance appear to be the weakest within these three categories even though the effect of time management on outcomes such as job performance was not clearly established (Claessens, Eerde, Rutte \& Roe, 2007).

The fifth hypothesis predicted that workers attitude towards time and work will jointly and independently have significant influence on perceived job performance in the public sector. This was tested jointly and not supported by the result obtained from the study carried out which rejects the hypothesis. Results revealed that there is no joint significant and independent influence of workers' attitude towards time and work on perceived job performance in the public sector. It relatively show a clear distinction in the relationship of workers' attitude towards time and perceived job performance of private sector workers from that of public sector workers, which means that private sector workers shows favourable relationship than public sector workers. It can be deduced from these findings that both private and public sector workers don't understand the interpretation of the output and quality of job or the output and input provided to create the output.

\section{Conclusion}

The study revealed that there is no difference in the attitude of workers towards time among private and public sector workers. It is therefore important for private and public organization to know how to allocate time to the workers in performing their assigned responsibilities, and how they perform on their job.

The study also revealed that there is a significant difference in the attitude of workers towards work among private and public sector workers. This means that owners of organizations should enlighten their workers on the more reason why they have to be contented with their job because a satisfied worker tends to perform better in his/her work.

It can also be deduced from the study carried out that there is no significant difference in workers' perceived job performance among private and public sector workers which means that both private and public sector workers have the same way of perceiving their job performance.

The study revealed further that there is a significantly joint influence of workers' attitude towards time and work on perceived job performance in the private sector, although there is a significant independent influence of workers attitude towards time on perceived job performance in the private sector but it does not apply to workers attitude towards work which showed that there is no significant independent influence of workers attitude towards work on perceived job performance in the private sector.

Findings from this study revealed that there is no significantly joint and independent influence of workers' attitude towards time and work on perceived job performance in the public sector which indicates that public sector workers' attitude towards time and work does not have any influence on their perceived job performance, contrary to the private sector workers' attitude towards time and work that has a joint influence on perceived job performance with the worker's attitude towards time having the only independent influence in perceived job performance.

\section{Recommendations}

Private and public organizations should ensure that their workers are aware of how planning, setting priorities \& deadlines, and learning how to improve time-saving habits \& behaviours will help in enhancing their perceived job performance.

It is also important for private and public organizations to organize seminars, conferences and enlightenment programmes for their workers in order to remind them about the importance of the use of time and work efficiency.

Nonetheless, private and public organizations need to formally or informally evaluate the attitude of their workers towards the use of time and towards their extent of job satisfaction.

\section{References}

Bateman, T.S. \& Organ, D.W. (1983). Job satisfaction and the good soldier: The relationship between effect and employee citizenship. Academy of Management Journal. 26, 587-595. http://dx.doi.org/10.2307/255908

Brown, S.P. \& Leigh, T.W. (1996). A new look at psychological climate and its relationship to job inducement, effort and performance. Journal of Applied Psychology. 81(4), 358-68. http://dx.doi.org/10.1037/0021-9010.81.4.358

Brown, S.P. \& Peterson, R.A. (1993). Antecedents and Consequences of Salesperson Job Satisfaction: Meta-Analysis and Assessment of Causal Effects. Journal of Marketing Research. 30, 63-77. http://dx.doi.org/10.2307/3172514 
Christen, M., Iyer, G., \& Soberman, D. (2006). Job Satisfaction, Job Performance, and Effort: A Re-examination using Agency Theory. Journal of Marketing Research. 70, 147.

Claessens, B.J.C., Eerde, W.V., Rutte, C.G., \& Roe, R.A. (2007). A review of the time management literature. Emerald Group Publishing Limited, 255-276.

Distasio, A.W. (1985). Time Management, Leadership Styles, and Selected Demographic Factors of Connecticut School Superintendents. University of Connecticut, 266.

Dunnettech, M.D. (1978). Handbook of Industrial and Organisatioanl Psychology. Chicago: Band Mcnally.

Islam, M.M., Depositario, W.C. \& Valera, J.B. (1987). Factors of job performance of the Barangay Council Officials of Laguna Province, Philippines. Indian Journal of Extension Education. 23 (3\& 4), 7-18.

Mogaji, A.A. (1997). Effects of Organizational Climate on Employees Commitment, Involvement and Motivation In Some Nigerian Manufacturing Industries. University of Lagos.

Muchinsky, P.M. \& Laffaldano, M.T. (1985). Job satisfaction and job performance: A Meta-Analysis. Psychological Bulletin. 97, 336-73.

Noon, J.J. (1985). The busy manager's action plan for effective self-management. England: Van Nostrand Reinhold (UK) Co. Ltd.

Oluwafemi, A.A. (2008). Attitude to work and job performance in public and private sectors. University of Ado-Ekiti.

Organ, D.W. (1977). A reappraisal and reinterpretation of the satisfaction causes performance hypothesis. Academy of Management Review. 2, 46-53.

Radhakrishna, R.B., Baggett, C.D., \& Toder, E. (1989). Time management and job performance of Maryland County Extension Directors. University Park: Pennsylvania State, Department of Agricultural and Extension Education.

Rain, J. S., Lane, I.M. \& Steiner, D.D. (1991). A current look at the job satisfaction/life satisfaction relationship: Review and future considerations. Human Relation. 44(5), 287-307. http://dx.doi.org/10.1177/001872679104400305

Rode, J. C. (2004). Job satisfaction and life satisfaction revisited: A longitudinal test of an Integrated Model. Human Relations. 57(9), 1205-1231. http://dx.doi.org/10.1177/0018726704047143

Schriber, J.B. \& Gutek, B.A. (1987). Some time dimensions of work: Measurement of an underlying aspect of organisational culture. Journal of Applied Psychology. 72(4), 642-50. http://dx.doi.org/10.1037/0021-9010.72.4.642

Smith, P.C., Kendall, L.M., \& Hulin C.L. (1969). The measurement of satisfaction in work and retirement. Chicago: Rand-Mcnally.

Taylor, W. F. (1911). Principles of Scientific Management. [Online]. Available: http://www.netmba.com/mamt/scientific.

Wanous, J.P. (1974). A causal correlation analysis of job satisfaction and performance relationship. Journal of Applied Psychology. 59, 139-44. http://dx.doi.org/10.1037/h0036532

Weiss, D. J., Dawis, R.V., England, G. W. \& Lofquist, L. H. (1967). Manual for Minnesota Satisfaction Questionnaire Minnesota: IRC, University of Minnesota.

Weiss, H. M. (2002). Deconstructing job satisfaction, separating evaluations, beliefs and effective experiences. Human Resource Management Review. 12(7), 173-194. http://dx.doi.org/10.1016/S1053-4822(02)00045-1

Table 1

\begin{tabular}{|l|l|l|l|}
\hline Time management dimension & $\mathrm{N}$ & Mean & SD \\
\hline Work environment & 47 & 2.89 & .46 \\
\hline Staff supervision & 49 & 3.03 & .31 \\
\hline Communications & 48 & 3.81 & .42 \\
\hline Planning and goals & 47 & 2.98 & .39 \\
\hline Self-management & 47 & 3.02 & .48 \\
\hline Total score & 44 & 3.23 & .31 \\
\hline
\end{tabular}

(University Park: Penn State, Department of Agricultural and Extension Education, 1989) 
Table 2

\begin{tabular}{|l|l|l|l|l|}
\hline (CED) Job Performance & \multicolumn{2}{|l|}{ Self(CED) ratings } & \multicolumn{2}{l|}{ Superior (ARD) rating } \\
\hline Dimensions & Mean & SD & Mean & SD \\
\hline Budget & 4.38 & .45 & 3.89 & .59 \\
\hline Programming & 4.19 & .40 & 3.74 & .73 \\
\hline Coordination & 4.12 & .55 & 3.65 & .73 \\
\hline Job knowledge & 4.04 & .44 & 3.66 & .85 \\
\hline Communication & 4.02 & .49 & 3.38 & .89 \\
\hline Leadership & 3.66 & .35 & 3.36 & .66 \\
\hline Supervision & 3.52 & .30 & 3.01 & .59 \\
\hline
\end{tabular}

(University Park: Penn State, Department of Agricultural and Extension Education, 1989)

Table 3

\begin{tabular}{|l|l|l|}
\hline Scales & American samples & Nigerian samples \\
\hline I & 0.86 & 0.69 \\
\hline E & 0.80 & 0.82 \\
\hline G & 0.90 & 0.94 \\
\hline
\end{tabular}

Table 4. Summary table of independent t-test analysis showing the difference in the attitude of workers towards time in private and public sectors

\begin{tabular}{|l|l|l|l|l|l|l|l|}
\hline Variables & $\mathrm{N}$ & $\mathrm{X}$ & $\mathrm{SD}$ & $\mathrm{St}$ & $\mathrm{Df}$ & $\mathrm{T}$ & $\mathrm{P}$ \\
\hline Private & 90 & 56.27 & 5.14 & 0.54 & & & \\
\cline { 1 - 5 } Public & 90 & 55.58 & 5.69 & 0.60 & \multirow{2}{*}{178} & \multirow{2}{*}{0.85} & $>.05$ \\
\hline
\end{tabular}

$\mathrm{t}(178)=0.85, \mathrm{p}>.05$

Table 5. Summary table of independent t-test analysis showing the significant difference in the attitude of workers towards work in private and public sectors

\begin{tabular}{|l|l|l|l|l|l|l|l|}
\hline Variables & $\mathrm{N}$ & $\mathrm{X}$ & $\mathrm{SD}$ & $\mathrm{St}$ & $\mathrm{df}$ & $\mathrm{T}$ & $\mathrm{P}$ \\
\hline Private & 90 & 70.20 & 12.79 & 1.35 & 178 & 2.85 & $<.01$ \\
\hline Public & 90 & 64.23 & 15.17 & 1.60 & & & \\
\hline
\end{tabular}

$\mathrm{t}(178)=2.85, \mathrm{p}>.01$

Table 6. Summary table of independent t-test analysis showing the significant difference in workers perceived job performance in private and public sectors

\begin{tabular}{|l|l|l|l|l|l|l|l|}
\hline Variables & $\mathrm{N}$ & $\mathrm{X}$ & $\mathrm{SD}$ & $\mathrm{St}$ & $\mathrm{df}$ & $\mathrm{T}$ & $\mathrm{P}$ \\
\hline Private & 90 & 35.41 & 4.41 & 0.46 & 178 & 1.45 & $>.05$ \\
\hline Public & 90 & 35.37 & 5.20 & 0.55 & & & \\
\hline
\end{tabular}

$\mathrm{t}(178)=1.45, \mathrm{p}>.05$ 
Table 7. Summary table of regression analysis showing the significant influence workers' attitude towards time and work will jointly and independently have on perceived job performance in the private sector

\begin{tabular}{|l|l|l|l|l|l|l|l|}
\hline Variables & & $\mathrm{T}$ & $\mathrm{P}$ & $\mathrm{R}$ & $\mathrm{R}^{2}$ & $\mathrm{~F}$ & $\mathrm{P}$ \\
\hline Constant & & 4.02 & & & & & \\
\cline { 1 - 5 } Time & .223 & 2.14 & $<.05$ & \multirow{2}{*}{.303} & .092 & 4.41 & $<.05$ \\
\cline { 1 - 5 } Work & .162 & 1.55 & $>.05$ & & & & \\
\hline
\end{tabular}

Table 8. Summary table of regression analysis showing the significant influence workers' attitude towards time and work will jointly and independently have on perceived job performance in the public sector

\begin{tabular}{|l|l|l|l|l|l|l|l|}
\hline Variables & & $\mathrm{T}$ & $\mathrm{P}$ & $\mathrm{R}$ & $\mathrm{R}^{2}$ & $\mathrm{~F}$ & $\mathrm{P}$ \\
\hline Constant & & 6.79 & & & & & \\
\cline { 1 - 5 } Time & -.08 & -.74 & $>.05$ & 0.93 & .009 & .38 & $>.05$ \\
\cline { 1 - 5 } Work & -.04 & -.39 & $>.05$ & & & & \\
\hline
\end{tabular}

